\title{
Quality of Life 10 Years after Sleeve Gastrectomy: A Multicenter Study
}

\author{
Daniel Moritz Felsenreich ${ }^{a} \quad$ Gerhard Prager $^{a} \quad$ Ronald Kefurt ${ }^{a}$ \\ Magdalena Eilenberg ${ }^{a} \quad J^{\prime} u_{i a}$ Jedamzik ${ }^{a} \quad$ Philipp Beckerhinn ${ }^{c}$ \\ Christoph Bichler $^{\mathrm{a}} \quad$ Christoph Sperker $^{\mathrm{b}}$ Michael Krebs $^{\mathrm{d}}$ \\ Felix Benedikt Langera \\ aDivision of General Surgery, Department of Surgery, Vienna Medical University, Vienna, \\ Austria; ${ }^{b}$ Department of Surgery, Rudolfstiftung Hospital, Vienna, Austria; 'Department of \\ Surgery, Hollabrunn Hospital, Hollabrunn, Austria; ${ }^{d}$ Division of Endocrinology, Department \\ of Internal Medicine, Vienna Medical University, Vienna, Austria
}

\section{Keywords}

Sleeve gastrectomy · Quality of life - Long-term follow-up - Reflux · Bariatric Quality of Life Index Short Form 36

\begin{abstract}
Objective: Sleeve gastrectomy (SG) has recently become the most commonly applied bariatric procedure worldwide. Substantial regaining of weight or severe reflux might compromise quality of life (QOL) after SG in the long-term follow-up. Long-term data on patients' QOL is limited, even though the persistent improvement in QOL is one of the aims of bariatric surgery. The objective of this study was to present patients' QOL 10 years after SG. Methods: Of 65 SG patients with a follow-up of $\geq 10$ years after SG who were asked to fill out the Bariatric Quality of Life Index (BQL) and Short Form 36 (SF36) questionnaires, 48 (74\%) completed them. This multicenter study was performed in a university hospital setting in Austria. Results: The BQL score revealed nonsignificant differences between the patients with $>50 \%$ or $<50 \%$ excess weight loss (EWL). It did show significant differences between patients with and without any symptoms of reflux. Patients with $<50 \%$ EWL scored significantly lower in $3 / 8$ categories of SF36. Patients suffering from reflux had significantly lower scores in all categories. Conclusions: EWL and symptomatic reflux impair patients' long-term QOL after SG.
\end{abstract}


Felsenreich et al.: QOL 10 Years after Sleeve Gastrectomy

\section{Introduction}

Laparoscopic sleeve gastrectomy (SG) is a restrictive bariatric procedure developed from vertical-banded gastroplasty and the Magenstrasse and Mill procedure, and it was first described by Marceau et al. [1] in 1993 as part of a biliopancreatic diversion with duodenal switch. The number of SGs performed has continually increased over the last decade and, as of recently, counts as the most common bariatric procedure worldwide. In Austria, however, SG is still outnumbered by laparoscopic Roux-en-Y gastric bypass (RYGB) [2].

When looking into the long-term follow-up of SG, 2 issues have recently been discussed by a number of authors: reflux and weight regain. The occurrence of reflux varies according to the length of the follow-up. DuPree et al. [3], for example, found reflux in $8.6 \%$ of their patients at 3 years while Boza et al. [4], in a study covering 5 years of follow-up, found it in $26.7 \%$. After initially good weight loss results, weight regain can be observed a number of years after SG, as in Himpens et al. [5], where the excess weight loss (EWL) of 77.5\% after 3 years decreased to $53.3 \%$ after 6 years. In our previous study, 59\% of the participating converted and nonconverted patients had regained $\geq 10 \mathrm{~kg}$ of their weight after 10 years [6].

Along with weight loss and the remission of comorbidities, improved QOL certainly is one of the essential aims of bariatric surgery. Therefore, it makes sense to study to what extent a certain procedure, in this case SG, is actually capable of improving a patient's QOL. In most cases, patients' QOL is measured shortly after the bariatric procedure (e.g., Fezzi et al. [7]). However, there are hardly any studies on how patients' QOL develops over a longer period of time. Juodeikis and Brimas [8], who reviewed current long-term studies on SG, concludes that there are few data available on QOL after SG. He therefore recommends treating the existing data with caution.

This study is one of the first to present long-term results regarding QOL after SG with a follow-up of $\geq 10$ years. This study also evaluates the impact of the long-term side effects associated with SG. The positive impact of bariatric surgery on patients' QOL is a well-known fact. Our focus here is a differentiated view of the factors that may influence patients' QOL after SG in a long-term follow-up.

\section{Material and Methods}

This study included all patients who underwent SG in 3 Austrian bariatric centers between January 2003 and December 2006, except for those who were converted to different procedures within the last 10 years. Participants were called in to complete the questionnaires, starting from January 2016. As it is mandatory for Austrians to inform the Central State Registry about their current home address, the majority of nonconverted patients $(n=$ 48; 74\%) could be reached and agreed to participate.

\section{Questionnaires}

We deployed 5 questionnaires commonly used in the follow-up to bariatric surgery: the Bariatric Analysis and Reporting Outcome System (BAROS), the Reflux Symptom Index (RSI), the Gastrointestinal Quality of Life Index (GIQLI), the Bariatric Quality of Life Index (BQL), and the Short Form 36 (SF36). The results of BAROS, which focuses on the outcomes of bariatric procedures, have already been published [6] and those of RSI and GIQLI, which are mainly reflux-related questionnaires, will be presented separately [9]. As SF36 and BQL evaluate patients' QOL on a more general level, their results are covered separately in this paper. 
Table 1. Patients' characteristics

\begin{tabular}{lc}
\hline & Nonconverted patients $(n=65)^{\mathrm{a}}$ \\
\hline At the time of sleeve gastrectomy & \\
Median age, years & $41.1 \pm 12.8$ \\
Female sex, \% & 75.0 \\
Weight, kg & $138.2 \pm 26.2$ \\
BMI & $48.7 \pm 9.1$ \\
At 10 years & $99.6 \pm 20.7$ \\
Weight, kg & $35.5 \pm 6.7$ \\
BMI & 131.8 \\
Median post OP time, months & \\
\hline \multirow{2}{*}{ a $67 \%$ (4 deceased patients were removed from the statistical calculation). } \\
\hline
\end{tabular}

The SF36 is a validated questionnaire consisting of 36 items about a patient's general QOL. The questions are grouped around 8 different areas, with a varying number of items for each field: physical functioning, social functioning, physical problems, emotional problems, mental health, energy and vitality, pain, and general perception of health. A value between 0 and 100 can be reached in each area $[10,11]$.

The BQL was developed in 2005 and updated in 2009. It measures a patient's QOL before and after a bariatric procedure and consists of 2 parts. The first part is a compilation of the medical data. The second part is dedicated to collecting data; it consists of 13 questions and a total of 65 points $(100 \%)$ may be reached. Its creators describe it as an easy tool to gather information about bariatric patients' postoperative QOL and superior to other questionnaires (e.g., GIQLI and BAROS) due to better responsiveness $[12,13]$.

\section{Statistical Analysis}

Data in this study are presented as median and range, mean and standard deviation, or percentage. The $\chi^{2}$ test and nonparametric Mann-Whitney U test were used for the comparison of groups of data. Univariate analyses were two-tailed and significance was set at a $p$ value of $<0.05$. SPSS $v 24$ for Windows ${ }^{\circledR}$ was used for statistical calculations.

\section{Results}

A total of 103 patients received SG in 1 of the 3 participating Austrian bariatric centers between January 2003 and December 2006. Eighty-eight patients had SG as their first bariatric procedure, and 13 were converted from laparoscopic adjustable gastric banding (LAGB) and 1 each from endoscopic gastric balloon placement and gastric stimulation. Thirty-four patients (33\%) were converted to RYGB within this period due to weight regain or reflux and were thus not included in the study. Four patients died from causes unrelated to SG within the follow-up period and were thus removed from the study. Forty-eight (74\%) of the remaining 65 patients completed the questionnaires. For details on patient characteristics, refer to Table 1.

This study focuses on whether symptomatic reflux as a side effect of SG and percentage EWL significantly impair patients' QOL $\geq 10$ years after the procedure. Twenty-five of the participating patients were suffering from reflux ( 19 had no symptoms), 24 had a $>50 \%$ EWL (group 1), 18 had an EWL of 25.0-49.9\% (group 2), and 6 had a 25.0\% EWL (group 3) at the time of completing the questionnaires. 
60

50

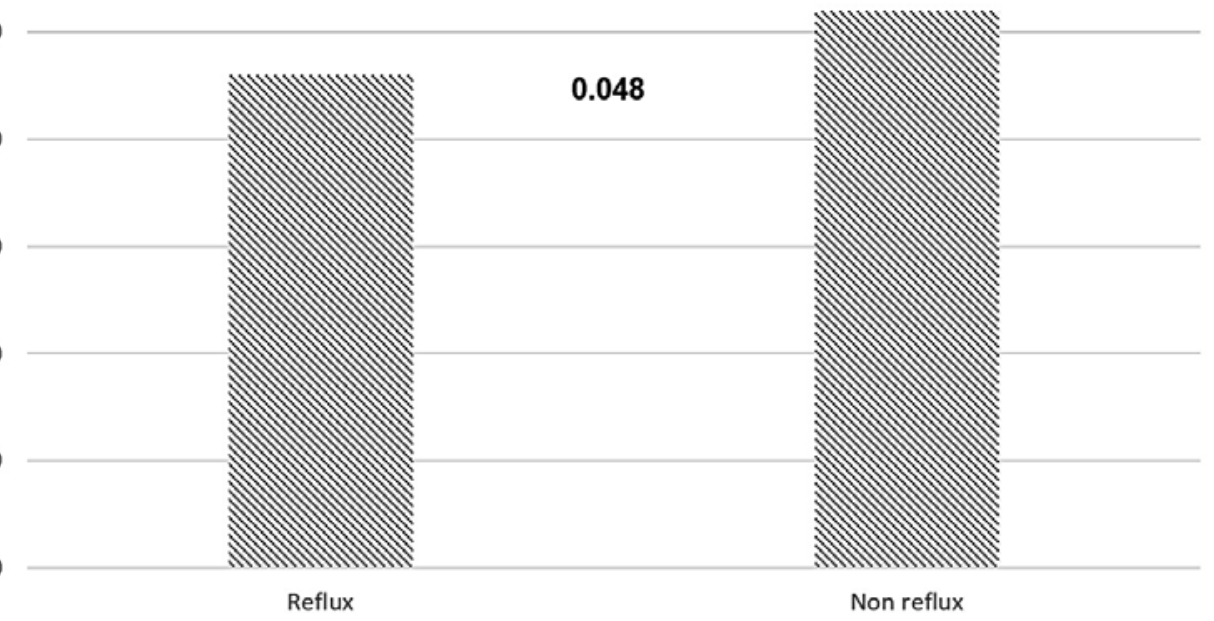

Fig. 1. BQL results of patients with and without reflux $(n=48)$.

Table 2. Questionnaire results in patients with and without reflux

\begin{tabular}{lllll}
\hline & $\begin{array}{l}\text { Total } \\
(n=48)\end{array}$ & $\begin{array}{l}\text { With reflux } \\
(n=27) 56.3 \%\end{array}$ & $\begin{array}{l}\text { Without reflux } \\
(n=21) 43.7 \%\end{array}$ & $p$ value \\
\hline SF36 & & & & 0.02 \\
$\quad$ PF (physical functioning) & $78.2 \pm 22.4$ & $71.4 \pm 26.3$ & $87.5 \pm 10.2$ & 0.002 \\
RP (role physical) & $75.6 \pm 37.2$ & $61.0 \pm 42.7$ & $95.8 \pm 9.6$ & 0.02 \\
BP (body pain) & $72.0 \pm 30.4$ & $62.9 \pm 34.2$ & $84.7 \pm 18.4$ & 0.02 \\
GH (general health) & $60.1 \pm 20.9$ & $54.0 \pm 22.0$ & $68.6 \pm 16.3$ & 0.04 \\
VT (vitality) & $55.5 \pm 22.0$ & $49.6 \pm 22.5$ & $63.6 \pm 19.0$ & 0.05 \\
SF (social functioning) & $79.9 \pm 27.3$ & $73.0 \pm 30.8$ & $89.6 \pm 18.3$ & 0.05 \\
RE (role emotional) & $72.1 \pm 41.7$ & $61.3 \pm 46.8$ & $87.0 \pm 23.3$ & 0.005 \\
MH (mental health) & $68.7 \pm 21.9$ & $61.0 \pm 22.7$ & $79.3 \pm 16.0$ & 0.048 \\
BQL & & & $52.1 \pm 7.7$ & 0.7 \\
QOL & $48.2 \pm 9.8$ & $45.7 \pm 8.4$ & 5.4 & \\
\hline
\end{tabular}

SF36, Short Form 36; BQL, Bariatric Quality of Life Index; QOL, quality of life.

$B Q L$

The BQL revealed noteworthy differences in the perception of QOL between 2 sets of 2 groups of patients. First, significant differences could be found between patients suffering from reflux and those who did not, at the time of filling in the questionnaire (with reflux: 45.7 \pm 8.4 ; without reflux: $52.1 \pm 7.7 ; p=0.048$ ) (Table 2; Fig. 1 ).

Second, the total BQL score also showed differences between patients with $>50 \%$ or $<50 \%$ EWL (i.e, group 1 vs. groups $2+3$ ) but these were not significant. Patients with EWL $>50 \%$ scored $49.8 \pm 9.1$ on average, those with EWL $25.0-49.0 \%$ scored $45.9 \pm 12.5$, and those with $<25 \%$ EWL $47.8 \pm 5.6$ points (Table 3 ; Fig. 2). 


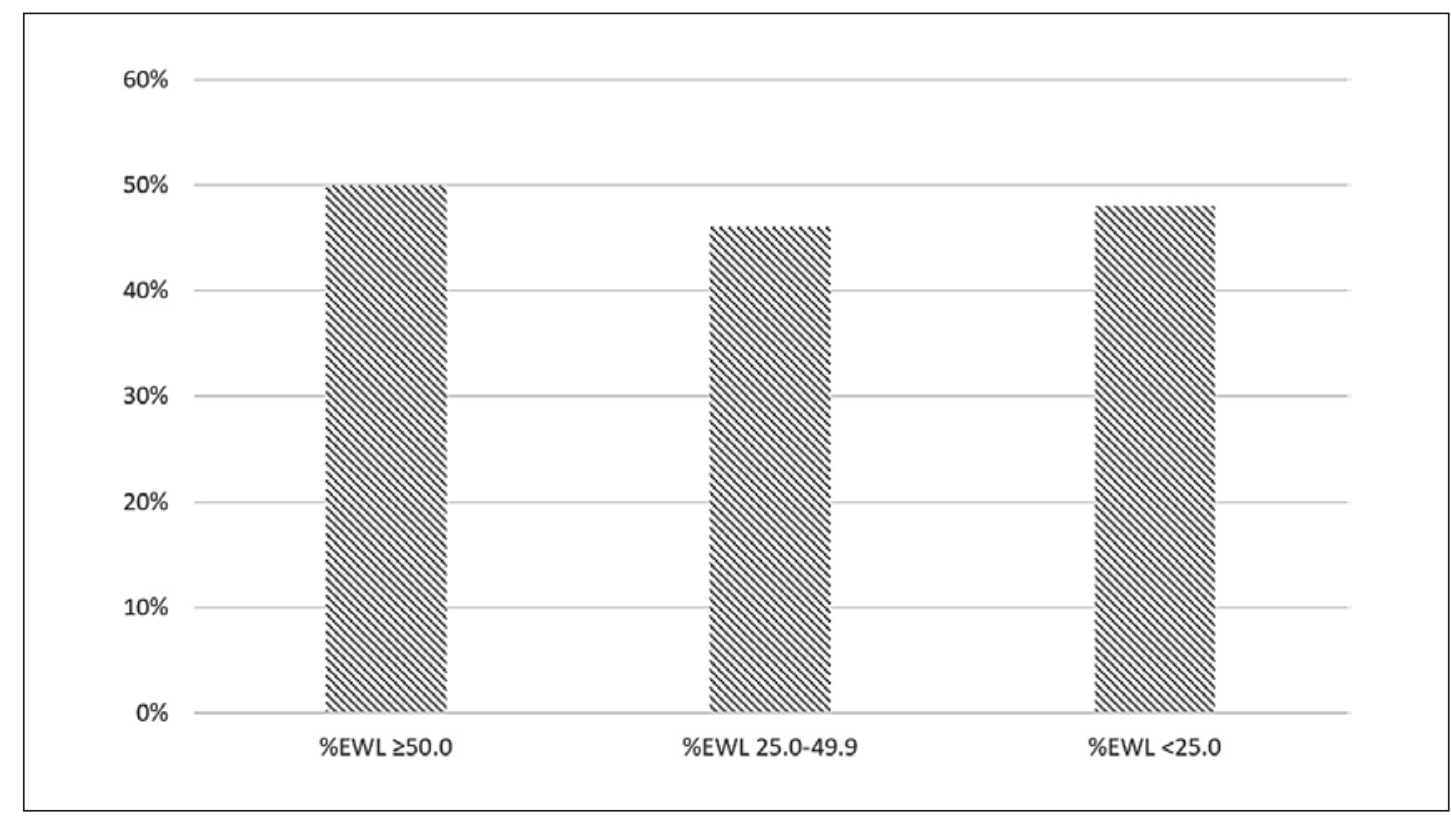

Fig. 2. BQL results of patients with $\geq 50 \%, 25.0-49.9 \%$, and $<25.0 \%$ EWL $(n=48)$.

Table 3. Questionnaire results according to percentage EWL

\begin{tabular}{llllll}
\hline & $\begin{array}{l}\text { Total } \\
(n=48)\end{array}$ & $\begin{array}{l}\text { Group 1 } \\
(n=24) 50 \%\end{array}$ & $\begin{array}{l}\text { Group 2 }^{\mathrm{b}} \\
(n=18) 37.5 \%\end{array}$ & $\begin{array}{l}\text { Group 3 } \\
(n=6) 12.5 \%\end{array}$ & $p$ value* \\
\hline SF36 & & & & & \\
$\quad$ PF (physical functioning) & $78.2 \pm 22.4$ & $81.4 \pm 20.9$ & $64.5 \pm 26.5$ & $64.3 \pm 33.3$ & $\mathrm{~ns}$ \\
$\quad$ RP (role physical) & $75.6 \pm 37.2$ & $82.2 \pm 26.1$ & $70.0 \pm 43.3$ & $65.0 \pm 22.4$ & $\mathrm{~ns}$ \\
$\quad$ BP (body pain) & $72.0 \pm 30.4$ & $82.8 \pm 32.1$ & $60.1 \pm 30.7$ & $62.6 \pm 14.3$ & 0.02 \\
GH (general health) & $60.1 \pm 20.9$ & $66.3 \pm 22.8$ & $55.9 \pm 20.2$ & $55.0 \pm 19.3$ & $\mathrm{~ns}$ \\
$\quad$ VT (vitality) & $55.5 \pm 22.0$ & $62.6 \pm 25.0$ & $50.0 \pm 20.8$ & $48.1 \pm 16.0$ & $\mathrm{~ns}$ \\
$\quad$ SF (social functioning) & $79.9 \pm 27.3$ & $83.6 \pm 22.5$ & $78.1 \pm 31.0$ & $73.6 \pm 17.7$ & $\mathrm{~ns}$ \\
$\quad$ RE (role emotional) & $72.1 \pm 41.7$ & $83.7 \pm 25.0$ & $62.5 \pm 45.4$ & $60.6 \pm 30.0$ & 0.04 \\
$\quad$ MH (mental health) & $68.7 \pm 21.9$ & $78.3 \pm 23.3$ & $61.8 \pm 22.1$ & $63.2 \pm 23.2$ & 0.04 \\
BQL & $48.2 \pm 9.8$ & $49.8 \pm 9.1$ & $45.9 \pm 12.5$ & $47.8 \pm 5.6$ & $\mathrm{~ns}$ \\
$\quad$ QOL & & & & & \\
\hline
\end{tabular}

SF36, Short Form 36; BQL, Bariatric Quality of Life Index; QOL, quality of life. * Comparison of group 1 vs. groups $2+3$. ${ }^{\mathrm{a}} \geq 50.0 \% \mathrm{EWL} ;{ }^{\mathrm{b}} 25.0-49.9 \% \mathrm{EWL} ;{ }^{\mathrm{c}}<25.0 \% \mathrm{EWL}$.

\section{SF36}

The results of the SF36 show that patients without reflux had a significantly better QOL in all 8 categories (Table 2; Fig. 3). Similarly, patients with $>50 \%$ EWL (group 1) had a higher score in all categories than those with $<50 \%$ EWL (groups $2+3$ ) in all categories. Differences were significant in 3 categories: body pain $(p=0.02)$, role emotional $(p=0.04)$, and mental health $(p=0.04)$ (Table 3; Fig. 4). 


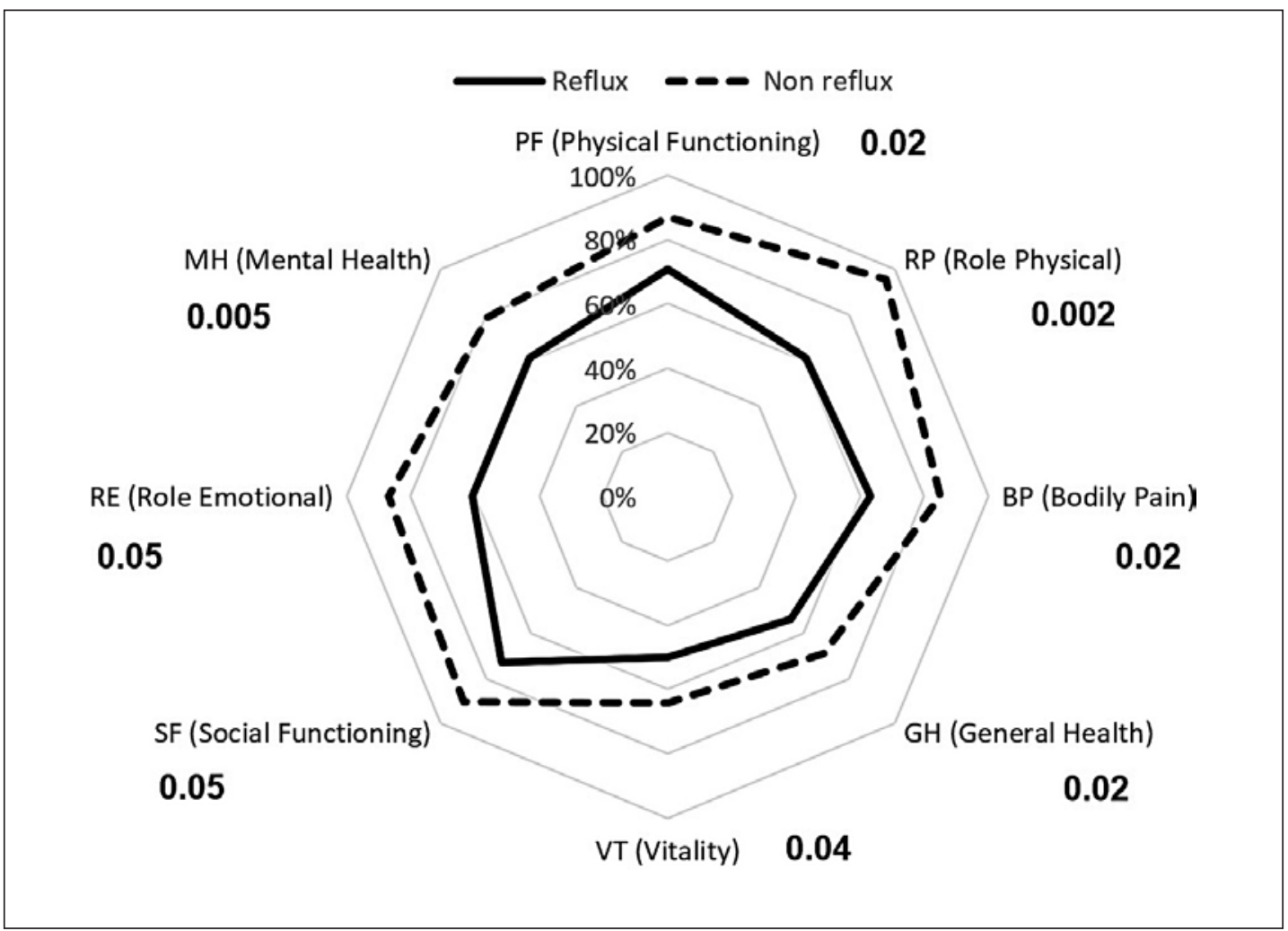

Fig. 3. SF36 results of patients with and without reflux $(n=48)$.

\section{Discussion}

This is the first study presenting long-term data on QOL after SG. Utilizing 2 validated questionnaires, the BQL and the SF36, we observed an impaired QOL in patients with significant weight regain and symptomatic reflux. Improved QOL, along with weight loss and a remission of comorbidities, is certainly one of the essential aims of bariatric surgery, which is why it makes sense to study to what extent bariatric procedures, in this case SG performed as sole and definitive bariatric procedure, are capable of improving a patient's QOL. Generally speaking, the patients in this study had quite low scores; this becomes even more evident when we compared our results to those of short-term studies.

$B Q L$

The BQL was developed in 2005 by Weiner et al. [12]. It was validated by a study on 133 patients and a follow-up of up to 12 months. A result of the study was that the BQL shows an exceptionally strong correlation with the results of the SF12 and slightly less of a correlation with BAROS, GIQLI, and EWL. The modified version of the BQL, which we used here, was presented in 2009 and validated in a similar study on 466 patients [13].

Matlach et al. [14] presented a retrospective long-term study on 153 patients who underwent LAGB. They used the BQL to assess QOL after a median follow-up of 8.7 years. The patients were divided into 3 groups: those who still had their gastric band, those who had had it removed, and those who had been converted to a different bariatric procedure. In all, $83.7 \%$ of the patients completed the BQL and it was found that a greater EWL meant patients experienced a significantly better QOL. 


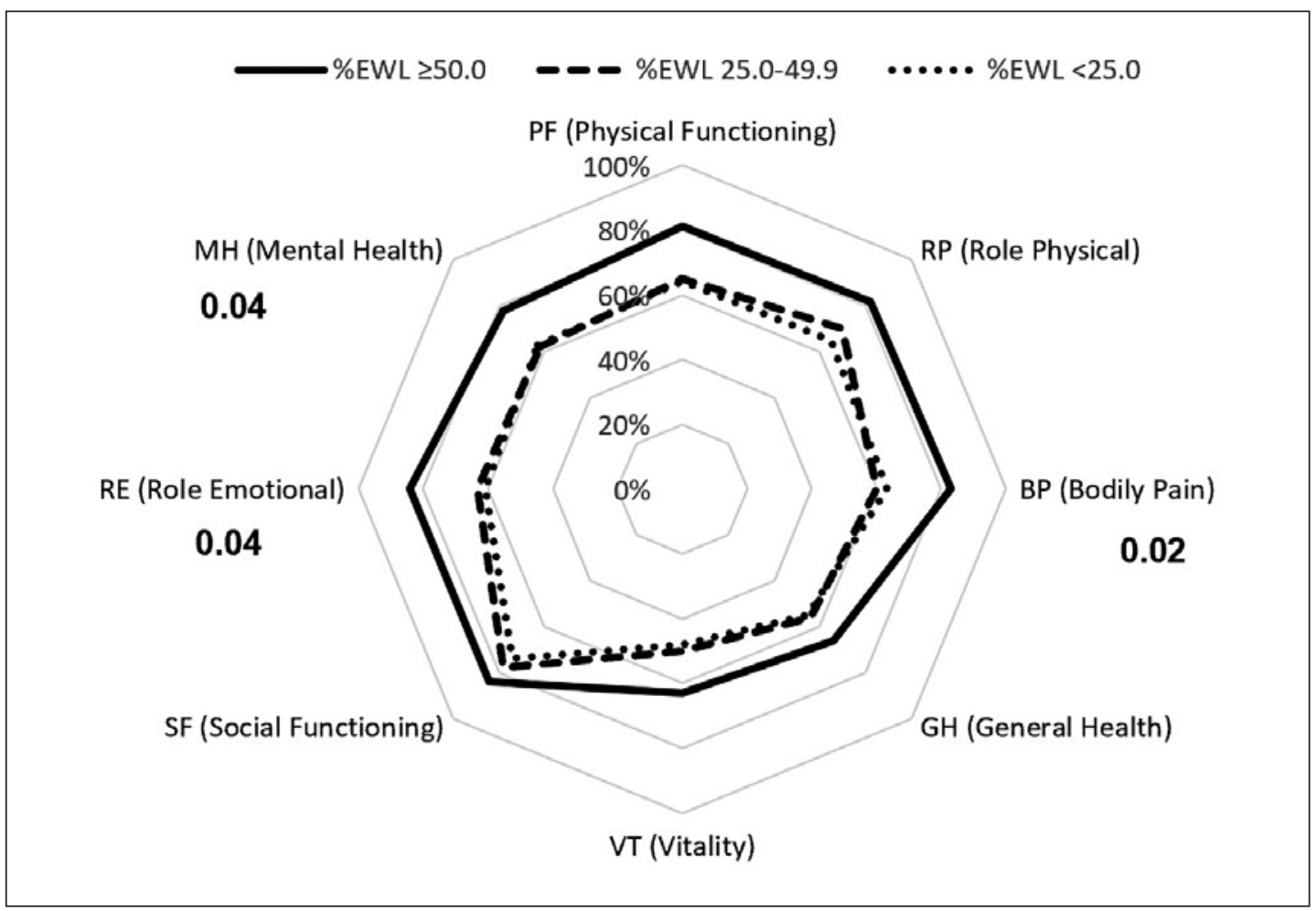

Fig. 4. SF36 results of patients with $\geq 50 \%, 25.0-49.9 \%$, and $<25.0 \%$ EWL $(n=48)$.

Accordingly, in this study, the BQL results revealed that 2 groups of patients had a better QOL 10 years after SG: those with a $>50 \%$ EWL and those who did not suffer from reflux (significant in the latter group). Interestingly, the patients suffering from reflux registered as a group with a significantly poorer QOL even though the BQL does not include any questions on reflux or reflux-related symptoms. It has been common knowledge for a while that reflux does, in many cases, occur as a side effect of weight regain. Most patients with a low percentage EWL (groups $2+3$ ) had weight regain. Thus, this study also shows that reflux is not only an uncomfortable symptom but does actually impair a person's QOL.

In the prospective randomized SM-BOSS study by Peterli et al. [15], patients' QOL, measured using the BQL among other scores, improved significantly when comparing the preoperative and postoperative results, at 1 and 2 years. However, the results at 3 years show a slightly poorer QOL. This tendency reflects the authors' theory that patients' QOL will improve shortly after SG but then continuously decrease over time.

In a study of 39 clinics and a total of 11,420 patients who underwent a bariatric procedure between 2008 and 2012, using the BQL and the Health and Activities Limitations Index preoperatively and at 1 year postoperatively, Waljee et al. [16] found a great deal of variation in their results. They concluded that these enormous differences in QOL perceived by patients were due to patient-related factors on the one hand and, interestingly, the performance of hospitals on the other.

Therefore, one might assume that after a long time, at least 10 years postoperatively in our case, the differences in QOL perceived by patients who have, in fact, all received the same procedure, would be widespread. However, as mentioned above, we found significant differences between patients with and without reflux. What our results also suggest is that the BQL is to be considered a potent score for bariatric patients. 
Felsenreich et al.: QOL 10 Years after Sleeve Gastrectomy

SF36

In a study on 78 consecutive SG patients who completed the SF36 preoperatively and 12 months' postoperatively, Fezzi et al. [7] found a significant improvement in patients' QOL in all areas of the questionnaire. The authors note, however, that this improvement was not consistently associated with the amount of weight lost. A limitation of the study was, as the authors also conclude, that it was a short-term study.

Nadalini et al. [17] presented a study with a longer follow-up. A total of 110 patients (34 underwent gastric banding, 69 RYGB, and 7 SG) completed the SF36 questionnaire preoperatively and at an average of 36 months' postoperatively. They found a significant improvement in all categories except for general and mental health. They also concluded that the category of physical function can be seen as a "significant predictor of weight loss," as they called it.

Flølo et al. [18] used the SF36 for SG patients postoperatively at 5 years. They summarized the results in 2 groups of physical and mental components and found that the scores of both significantly improved when compared to a cohort of preoperative patients.

D'Hondt et al. [19] studied 83 patients over a period of 6 years using the SF36 among other scores and compared the results of subjects with $>50 \%$ EWL to those with $<50 \%$ EWL. They found significant differences in the categories "physical functioning" and "general health." Like ours, their study shows that comparing different groups of patients postoperatively may be considered just as important as comparing preoperative to postoperative data, especially when it comes to QOL. While QOL may generally improve when comparing preand postoperative data, different groups of patients within a cohort may show varying developments in QOL over the follow-up period (e.g., patients with reflux vs. without; patients with weight regain vs. without; patients $>50 \%$ EWL vs. $<50 \%$ EWL; etc.).

In a study on 77 patients who completed the SF36 at 1, 3, and 5 years after SG, Strain et al. [20] found a significantly poorer QOL according to scores in the categories "physical function," "role physical," "body pain," "general health," "vitality" and "social function," when comparing the results over time which they associated with weight regain.

These findings correspond with our results for patients with a low percentage EWL. Patients with $>50 \%$ EWL generally showed a better QOL in the SF36, significantly so in the categories "body pain," "role emotional," and "mental health" than those with $<50 \%$ EWL. Patients with reflux, on the other hand, had significantly low scores in all categories. This suggests that patients experience reflux as actual physical pain as well as a source of constant discomfort, which impairs their mental well-being at the same time. It should be considered that most patients who suffer from reflux have prescriptions for proton pump inhibitors, the side effects of which have not been fully studied. However, in a prospective cohort study on 73,679 aged $\geq 75$ years in 2004-2011, Gomm et al. [21] found that dementia can be associated with the regular intake of proton pump inhibitors.

\section{Limitations of the Study}

Patients were not asked to fill in questionnaires before their procedures, which is why comparisons between their pre- and postsurgery QOL are not included in this study. A possible improvement in QOL after the procedure in some patients may thus have gone unnoticed. Of course, the improvement of patients' QOL after bariatric surgery has been well-researched. This paper presents a more differentiated view of the factors that can influence patients' QOL after SG in a long-term follow-up. 
Felsenreich et al.: QOL 10 Years after Sleeve Gastrectomy

\section{Conclusion}

A low EWL of $<50 \%$ may correspond to a poorer QOL after SG. Symptomatic reflux does significantly impair long-term QOL after SG. The SF36 and BQL proved to be appropriate tools to evaluate the long-term effects of SG on patients' QOL. Thus, we clearly recommend using these scores when focusing on patients' long-term QOL after bariatric surgery. Additionally, we suggest that they could be utilized in the evaluation of long-term outcomes of bariatric surgery and in the preparation of a conversion to other bariatric procedures. Both questionnaires may certainly also be used for the evaluation of single patients.

\section{Statement of Ethics}

The study was approved by the local Institutional Review Board, the Ethics Committee of the Medical University of Vienna (ref. No. 1434/2015) and with the 1964 Helsinki declaration and its later amendments or comparable ethics standards. Informed consent was obtained from all individual participants included in the study.

\section{Disclosure Statement}

The authors declare that they have no conflicts of interest.

\section{References}

1 Marceau P, Hould FS, Simard S, Lebel S, Bourque RA, Potvin M, et al. Biliopancreatic diversion with duodenal switch. World J Surg. 1998 Sep;22(9):947-54.

2 Angrisani L, Santonicola A, Iovino P, Vitiello A, Higa K, Himpens J, et al. IFSO Worldwide Survey 2016: Primary, Endoluminal, and Revisional Procedures. Obes Surg. 2018 Dec;28(12):3783-94.

3 DuPree CE, Blair K, Steele SR, Martin MJ. Laparoscopic sleeve gastrectomy in patients with preexisting gastroesophageal reflux disease: a national analysis. JAMA Surg. 2014 Apr;149(4):328-34.

4 Boza C, Daroch D, Barros D, Leon F, Funke R, Crovari F. Long-term outcomes of laparoscopic sleeve gastrectomy as a primary bariatric procedure. Surg Obes Relat Dis. 2014;10:1129-33.

5 Himpens J, Dobbeleir J, Peeters G. Long-term results of laparoscopic sleeve gastrectomy for obesity. Ann Surg. 2010 Aug;252(2):319-24.

6 Felsenreich DM, Langer FB, Kefurt R, Panhofer P, Schermann M, Beckerhinn P, et al. Weight loss, weight regain, and conversions to Roux-en-Y gastric bypass: 10-year results of laparoscopic sleeve gastrectomy. Surg Obes Relat Dis. 2016 Nov;12(9):1655-62.

7 Fezzi M, Kolotkin RL, Nedelcu M, Jaussent A, Schaub R, Chauvet MA, et al. Improvement in quality of life after laparoscopic sleeve gastrectomy. Obes Surg. 2011 Aug;21(8):1161-7.

8 Juodeikis Z, Brimas G. Long-term results after sleeve gastrectomy: a systematic review. Surg Obes Relat Dis. 2017;13:693-9.

9 Felsenreich DM, Kefurt R, Schermann M, Beckerhinn P, Kristo I, Krebs M, et al. Reflux, Sleeve Dilation, and Barrett's Esophagus after Laparoscopic Sleeve Gastrectomy: Long-Term Follow-Up. Obes Surg. 2017 Dec; 27(12):3092-101.

10 Jenkinson C, Coulter A, Wright L. Short form 36 (SF36) health survey questionnaire: normative data for adults of working age. BMJ. 1993 May;306(6890):1437-40.

11 Ware JE Jr, Sherbourne CD. The MOS 36-item short-form health survey (SF-36). I. Conceptual framework and item selection. Med Care. 1992 Jun;30(6):473-83.

12 Weiner S, Sauerland S, Fein M, Blanco R, Pomhoff I, Weiner RA. The Bariatric Quality of Life index: a measure of well-being in obesity surgery patients. Obes Surg. 2005 Apr;15(4):538-45.

13 Weiner S, Sauerland S, Weiner R, Cyzewski M, Brandt J, Neugebauer E. Validation of the adapted Bariatric Quality of Life Index (BQL) in a prospective study in 446 bariatric patients as one-factor model. Obes Facts. 2009;2 Suppl 1:63-6. 
14 Matlach J, Adolf D, Benedix F, Wolff S. Small-diameter bands lead to high complication rates in patients after laparoscopic adjustable gastric banding. Obes Surg. 2011 Apr;21(4):448-56.

15 Peterli R, Wölnerhanssen BK, Vetter D, Nett P, Gass M, Borbély Y, et al. Laparoscopic Sleeve Gastrectomy Versus Roux-Y-Gastric Bypass for Morbid Obesity-3-Year Outcomes of the Prospective Randomized Swiss Multicenter Bypass or Sleeve Study (SM-BOSS). Ann Surg. 2017 Mar;265(3):466-73.

16 Waljee JF, Ghaferi A, Finks JF, Cassidy R, Varban O, Carlin A, et al. Variation in Patient-reported Outcomes Across Hospitals Following Surgery. Med Care. 2015 Nov;53(11):960-6.

17 Nadalini L, Zenti MG, Masotto L, Indelicato L, Fainelli G, Bonora F, et al. Improved quality of life after bariatric surgery in morbidly obese patients. Interdisciplinary group of bariatric surgery of Verona (G.I.C.O.V.). G Chir. 2014 Jul-Aug;35(7-8):161-4.

18 Flølo TN, Andersen JR, Kolotkin RL, Aasprang A, Natvig GK, Hufthammer KO, et al. Five-Year Outcomes After Vertical Sleeve Gastrectomy for Severe Obesity: A Prospective Cohort Study. Obes Surg. 2017 Aug;27(8): 1944-51.

19 D’Hondt M, Vanneste S, Pottel H, Devriendt D, Van Rooy F, Vansteenkiste F. Laparoscopic sleeve gastrectomy as a single-stage procedure for the treatment of morbid obesity and the resulting quality of life, resolution of comorbidities, food tolerance, and 6-year weight loss. Surg Endosc. 2011 Aug;25(8):2498-504.

20 Strain GW, Saif T, Gagner M, Rossidis M, Dakin G, Pomp A. Cross-sectional review of effects of laparoscopic sleeve gastrectomy at 1, 3, and 5 years. Surg Obes Relat Dis. 2011;7:714-9.

21 Gomm W, von Holt K, Thomé F, Broich K, Maier W, Fink A, et al. Association of Proton Pump Inhibitors with Risk of Dementia: A Pharmacoepidemiological Claims Data Analysis. JAMA Neurol. 2016 Apr;73(4):410-6. 